\title{
An SEM study of the nuchal organ in Daphnia himalaya (nov. sp.) embryos and neonates collected from the Khumbu region (Nepalese Himalayas)
}

\author{
D. Carolina PEÑALVA-ARANA* and Marina MANCA ${ }^{1)}$
}

Department of Biology, Indiana University, Bloomington, IN 47405, USA

${ }^{1)}$ CNR Institute of Ecosystem Study, L.go Tonolli 52, 28922 Verbania Pallanza, Italy

*e-mail corresponding author: dcpenalv@indiana.edu

\begin{abstract}
Zooplankton from the Khumbu region in Nepal are rarely studied, and little is known regarding their morphology and physiology. During the EV-K ${ }^{2}$-CNR Project, a collaboration between the Government of the Republic of Italy and the Nepal Academy of Science and Technology (NAST) as part of "The long distance transport of micro-pollutants", zooplankton samples revealed the presence of small head shields' remains in the sediment possessing a hole in the dorsal margin. This observation led to the hypothesis that Daphnia himalaya neonates must possess a nuchal organ for osmoregulation in these alpine lakes. Here we report the presence of a nuchal organ in embryos and neonates, and explore its development, noting that the nuchal organ is retained up until the first post-embryonic moult. We also examine the chemistry of the lakes and in particular their conductivity, which is lower in lakes having D. himalaya than in lakes that do not (16 $\mu \mathrm{S}$ and $32 \mu \mathrm{S} \mathrm{cm}^{-1}$ respectively).
\end{abstract}

Key words: nuchal organ, sediment remains, SEM, Nepalese Himalayas

\section{INTRODUCTION}

The sediment remains of Daphnia himalaya, a dark pigmented Ctenodaphnia from alpine lakes in the Khumbu region (Nepalese Himalayas), have sparked an investigation into the occurrence and development of the nuchal organ. Analyses of sediment remains have not previously revealed the presence of the nuchal organ. Thus the lakes of the Khumbu region are special, as their chemical and physical properties allow these rarely seen head shields to survive degradation.

Reports of zooplankton of Nepalese alpine lakes can be traced back to the studies of Hedin (Hedin 1907) and the Yale North India Expedition in 1932, all of which described a dark pigmented Daphnia-like species which was reported as Daphnia tibetana (Wagler 1936) and has been recently re-described and renamed as Daphnia himalaya (Manca et al. 2006). This region has been a focus of the EV-K ${ }^{2}$-CNR Project as part of "The long distance transport of micro-pollutants" which due to the often simplified biological communities of alpine lakes makes them ideal for environmental studies. Although they typically contain low species diversity, the species found tend to be endemic and adapted to extreme environmental conditions, making them treasures of biological diversity. The species found in these extreme environments are rarely studied and often include intriguing species such as Daphnia himalaya.

The term nuchal organ was first used by Scourfield (1943, "Haft-organ") and similar external cuticular structures in the neck region, termed dorsal organ, nuchal organ, neck organ and head pores, have been described for various species of the Branchiopoda and for Crustacea in general. The location of the nuchal organ relative to the antennal muscles was suggested as a diagnostic trait to distinguish between Ctenodaphnia and Daphnia by Schwartz \& Hebert (1984), although later Benzie (2005), noting that D. lumholtzi (a Ctenodaphnia) has a Daphnia-like organ position, suggested that this organ may simply mark the joint between the cephalic and the dorsal shields on the dorsal margin.

Although previously reported in other Branchiopods as an osmoregulatory organ or gland (Meurice \& Goffinet 1983; Monoyer \& Bussers 1978), the function of the nuchal organ in Daphnia is still debated. This is due in part to its short lived existence and insufficient physiological evidence. Previous Daphnia research has investigated its ultrastructure as a means of deducing function and the currently ascribed function is ion transport for osmoregulation (Halcrow 1982; Peters 1987). To date the presence of the nuchal organ in $D$. himalaya from the zooplankton samples collected in the Khumbu region remains to be confirmed. It is the aim of the present paper to determine its occurrence and link it to physical and/or chemical properties of these remote lakes.

The zooplankton communities found in the lakes of the Khumbu region were collected on numerous expeditions to the region in the framework of the EV-K ${ }^{2}$-CNR Project (1992-2004). As part of the study, zooplankton and sediment samples were collected for the study of global changes and global scale transport of pollutants. During the study of the sediment, two types of head shields attributed to the Ctenodaphnia subgenus were 
found: one was the typical shield with a median groove characteristic of the subgenus, while the other was unusual, not previously reported in the literature, having a circular hole in the median region, proximal to the posterior median groove (Manca et al. 1999). Both were attributed to the same species $D$. tibetana (now renamed D. himalaya); however it was observed that the "holed" one belonged to a smaller size class, and that the head shields found lost the hole as they increased in size. From these observations, the authors concluded that those with the hole could be the remains of an early stage neonate possessing the so called "nuchal organ", as its location is similar to the previously reported nuchal organ of other branchiopod Crustacea. We present morphological evidence that $D$. himalaya embryos and neonates possess a nuchal organ and investigate the developmental stages associated with their presence. We also hypothesize that the nuchal organ of $D$. himalaya allows them to survive these extreme environments.

\section{METHODS}

A total of 90 lakes were identified in the watersheds of the Imja Khola and the Ngozumpa River, all referred to by a "Lake Cadastre Number" (LCN; Tartari et al. 1998). Twenty-six of the thirty-one lakes were sampled from the lake shore, with the other five (LCN9, 10, 29, 40 , and 70 ) being sampled from an inflatable rubber boat at three depths $(1 \mathrm{~m}$ below the surface, median depth, and $1 \mathrm{~m}$ above the bottom) at the maximum depth site. Zooplankton were collected using plankton nets (50 or $126 \mu \mathrm{m}$ mesh) by vertical hauls from the deepest point of the lakes or by horizontal hauls from the littoral region if a boat was not available. Samples were preserved in buffered $10 \%$ formaldehyde or $90 \%$ ethyl alcohol. $D$. himalaya was found in lakes 9, 29,66, and 70; all belong to the first basin and are high altitude lakes $(5213,5172$, 5020 and $4330 \mathrm{~m}$ a.s.l. respectively) (Manca et al. 1998).

$D$. himalaya at different developmental stages were sorted from lakes with the highest $D$. himalaya concentration (lakes 9 and 29) and dehydrated through an ethanol series and critical point dried (Balzer CPD 010). After the samples were dried, embryos of varying developmental stages were carefully removed from the brood chamber of gravid daphnids for further investigation. The dried samples were sputter coated with gold and imaged at $10 \mathrm{kV}$ using a LEO $435 \mathrm{VP}$.

For analysis of the physical and chemical properties of the lakes containing $D$. himalaya, we used the data reported by Tartari et al. (1998).

\section{RESULTS}

\subsection{Occurrence of the nuchal organ in embryos and neonates}

The presence of the nuchal organ was seen in both embryos (size: $0.29-0.38 \mathrm{~mm}$ ) and early instar stages of neonates (size range: $0.38-0.78 \mathrm{~mm}$ ) (Figs. 1 and 2). The overlap in size between the two suggests that size and age play a role in the presence of the nuchal organ. For determining the embryonic stage, Kotov \& Boikova's (2001) descriptions were used as reference. During early embryonic division, thus being round and not elongated, there was no sign of a nuchal organ (Fig. 1A). In the midembryonic stage, the nuchal organ was seen as a distinct ring just below the head bulge (Fig. 1B). In the late embryonic stage, the nuchal organ was well defined and medially located on the head shield, with the cuticle covering the nuchal organ terminating in a distinct groove around its perimeter (Figs 1D and 1E).

For neonates we divided the first instar stage into early and late. Late stage embryos and first instar neonates could be easily distinguished by their extension of the dorsal spine and the difference in the length and development of the swimming antennae (Fig. 2A) (Edmondson 1955). Early stage neonates retain the nuchal organ and it appears as an elevated area of the cuticle, even when viewed using conventional light microscopy and clearly visible using SEM (Figs 2B and 2C). The nuchal organ is seen externally as an expanded portion of the dorsal ridge or spine which runs from the front to the back of the head of the juvenile daphnid (Figs 2 and 3). Early stage neonates were distinguished from late stage first instar neonates by the disappearance of the nuchal organ's distinct outline, as though receding into the body (Figs 2C and $3 \mathrm{~A}$ vs. 3C). Both neonate stages continue to lack the traditional polygonal cuticular markings over the nuchal organ as seen on the rest of the carapace (Figs 2 and 3). Neonates loose their nuchal organ altogether after their first post-embryonic moulting (not shown).

\subsection{Physical and chemical properties of D. himalaya lakes}

Using the data collected through the EV-K²-C.N.R. Project we compared physical and chemical properties of the four lakes $(9,29,66$, and 70) known to have $D$. himalaya both in the water column and in the sediment (Tab. 1) (Tartari et al. 1998). Statistical analysis of conductivity of $D$. himalaya lakes versus those having other Daphnia showed a significant difference between the two (Fig. 4) $\left(\mathrm{P}=0.05\right.$, $\mathrm{t}$-test, $\mathrm{x}_{\text {himalaya }}=16.33$ and $\mathrm{x}_{\text {other }}=$ $\left.32 \mu \mathrm{S} \mathrm{cm}^{-1}\right)$. All other compared parameters showed no significant correlations.

\section{DISCUSSION AND CONCLUSIONS}

Embryonic and $1^{\text {st }}$ instar neonate $D$. himalaya from Himalayan lakes have a nuchal organ. Its distinct shape and location helps explain the presence of a hole in the medio-dorsal region of head shields remains found in the sediment of lakes in this region (Manca et al. 1999; Manca \& Comoli 2004).

Although the reason for the presence and the func- 

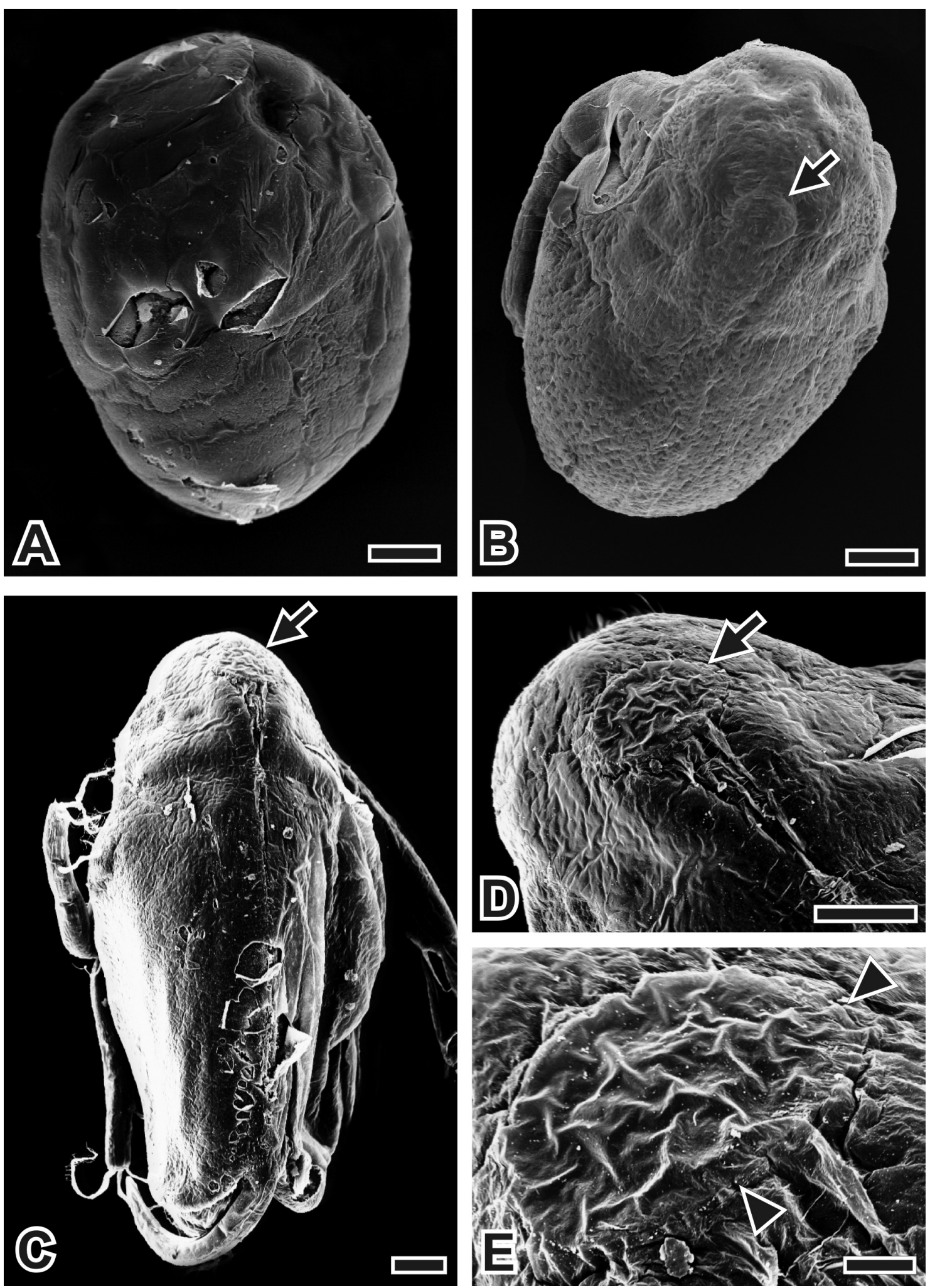

Fig. 1. Daphnia himalaya embryos and their nuchal organs. A: Early stage embryo, I instar, mostly round and lacking a differentiated nuchal organ; B: Middle stage embryo, II instar, with a well defined nuchal organ (arrow) on the dorsal margin of the head; C: Late stage embryo, IV instar, with distinct nuchal organ (arrow) and curved carapace spine; D and E: Close up of nuchal organ (arrow) from embryo seen in $\mathbf{C}$; note differentiation in cuticle between that inside the nuchal organ and rest of carapace, and grooved margin (arrowheads). 


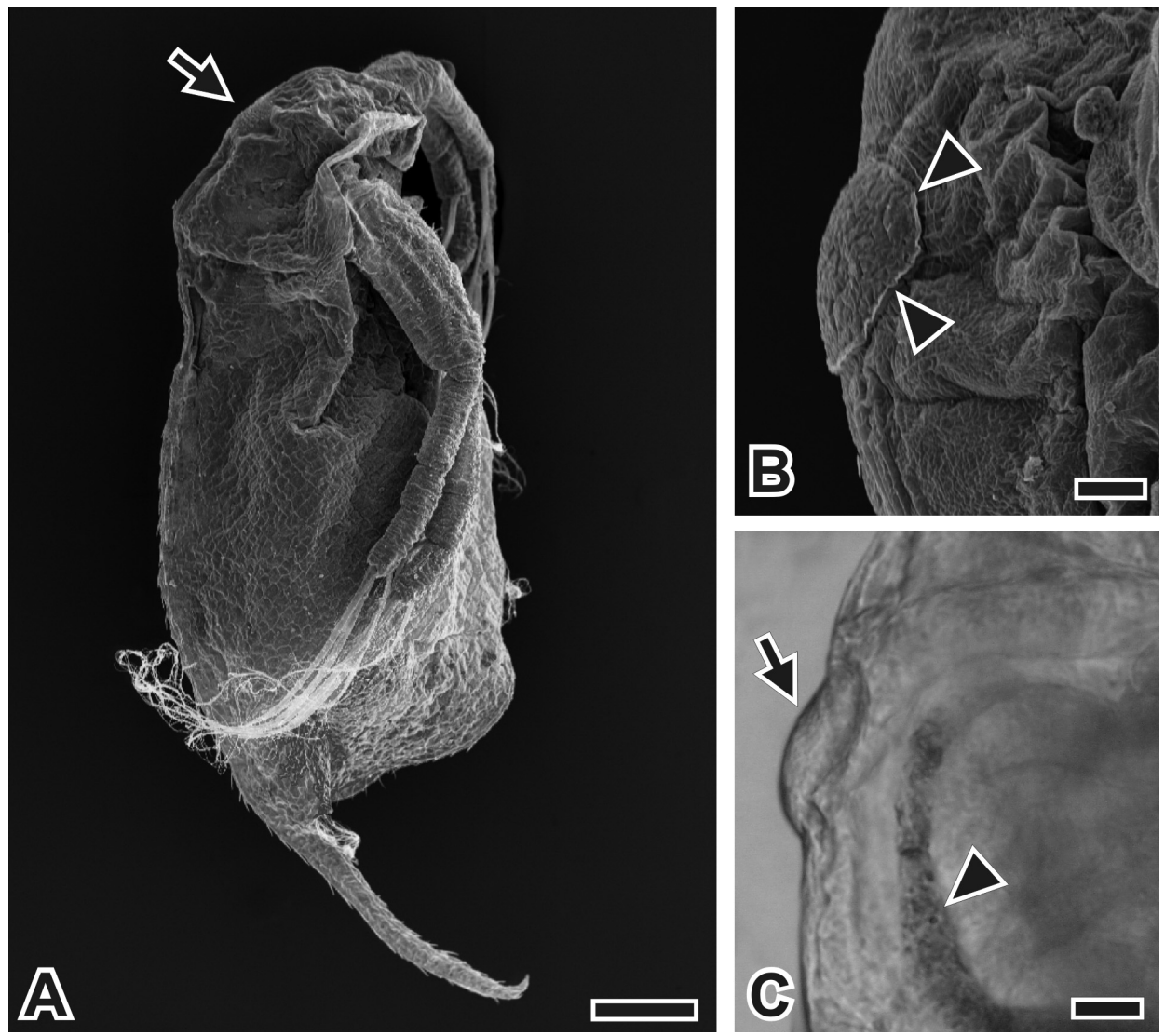

Fig. 2. Daphnia himalaya neonates and nuchal organ. A: Early stage of I instar neonate, slightly curved dorsal spine but fully developed swimming antennae, nuchal organ present (arrow). B: Light microscopy showing nuchal organ (arrow) and gut (arrowhead) of a neonate; note darkened gut showing successful feeding. C: early stage neonate with its respective nuchal organ with elevated edges (arrowheads).

tion of this organ is unknown in D. himalaya, previous research has shown that the nuchal organ found on various cladocera species, including D. magna, is committed to osmoregulation (Halcrow 1982; Aladin 1991, Halcrow 1985). It is believed to be essential for the osmotic regulation of the hemolymph through ion transport while in the brood chamber. Cladocera are able to osmoregulate their hemolymph, both hyper- and hypoosmotically, in fresh to slightly brackish and in marine waters, respectively. In marine organisms the nuchal organ can be active throughout the adult stage; however there is no trace of it in Daphnia adults. The organ is essential for the survivorship of embryos in the last two stages within the brood pouch as they are not able to feed and thus selfregulate ionic intake. After leaving the brood pouch, the young Cladocera begin to feed, and with the first postembryonic moulting the organ disappears (Aladin 1991; Halcrow 1982, 1985; Meurice \& Goffinet 1983). In general marine species and those with closed brood pouch, hypo-osmolarity is maintained by the pouch itself until the final stages of embryonic development, when the nuchal organ or the epipodites develop. At that moment, the marsupial fluid rises in ionic concentration to that of the surrounding sea or brackish water, and embryos must begin to self-regulate (Aladin 1991).

It is unknown if all so-called-Cladocerans (Fryer 1987) possess a nuchal organ but those that do, show the typical arrangement of a more or less circular cuticular area surrounded by an elevated rim which is also seen in some species of the Conchostraca and Anostraca. This neck organ morphology exists in the cladoceran order Onychopoda, and in Anomopoda (Macrothricidae; Daphniidae). In one species of the genus, Simocephalus, the nuchal organ is believed to be modified into an attachment organ, acting as a supplement to the normal antennal way of attachment (Meyer-Rochow 1979). Sida crystallina is the only species of Ctenopoda known to have a neck organ, and it is the most well documented example of a neck organ modified into an attaching device (Günzl 1978, 1980; Olesen 1996). The homology with the nuchal organ is not obvious from adult specimens but is apparent when juveniles are examined. Therefore it is important to understand not only the role of the nuchal organ but also its evolutionary development and change of function; this may add one more character to consider when reconstructing Cladoceran phylogeny. 

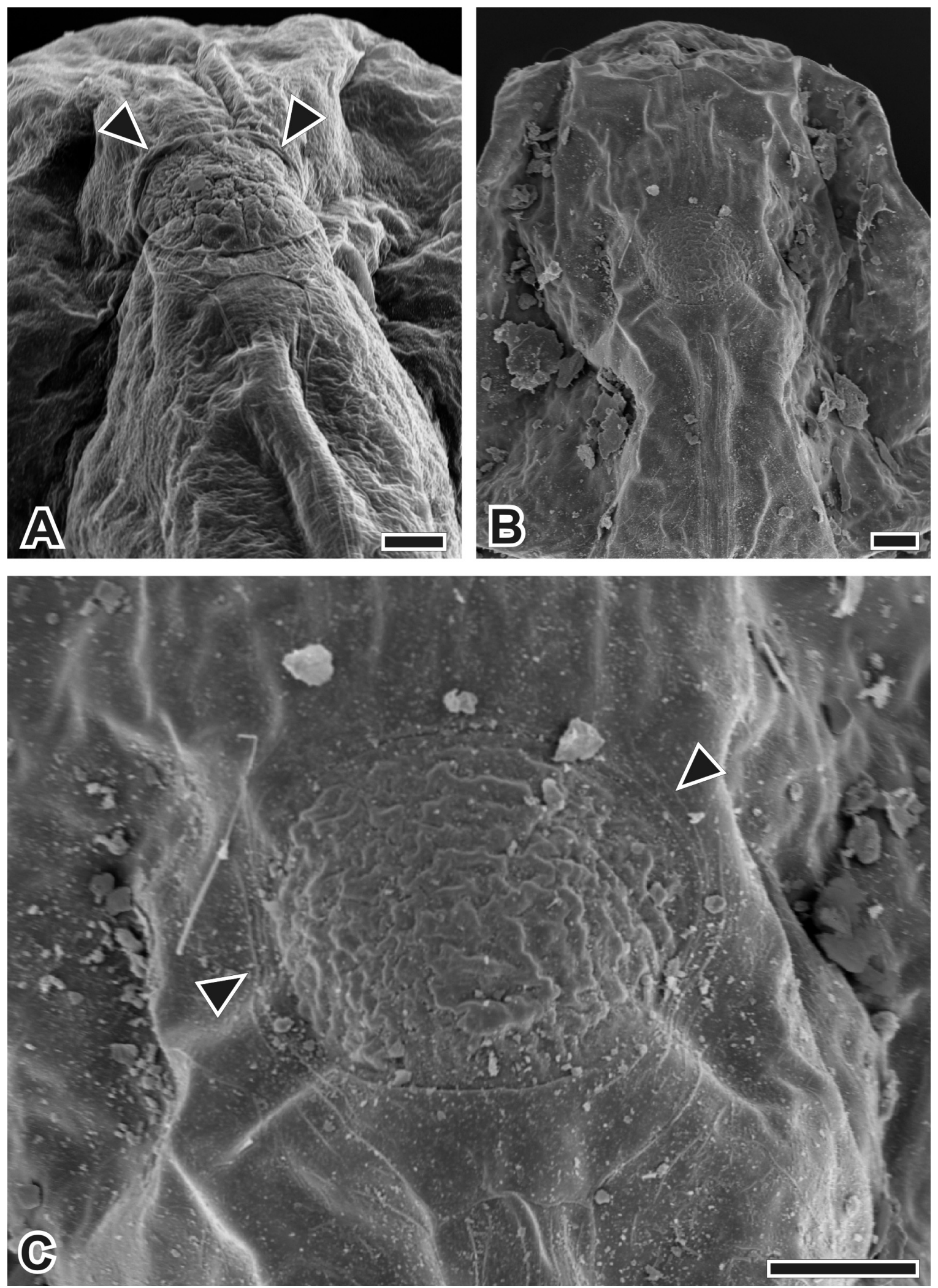

Fig. 3. A, B, \& C: late stage of first instar neonate, nuchal organ begins to recede into rest of carapace although still possessing a cuticle cover clearly distinct from rest of the carapace (arrowhead), note what appears almost to be concentric circles (arrow) around receding nuchal organ. 
Tab. 1. Morphometry and hydrochemistry of the four Himalayan lakes known to hold D. himalaya and their sediment remains (Tartari et al. 1998).

\begin{tabular}{lllll}
\hline Lake (Cadastre number) & 9 & 29 & 66 & 70 \\
Altitude (m a.s.1.) & 5213 & 5172 & 5020 & 4830 \\
Latitude N & $27^{\circ} 57^{\prime} 54^{\prime}$, & $27^{\circ} 53^{\prime} 26^{\prime}$, & $27^{\circ} 57^{\prime} 13^{\prime}$, & $27^{\circ} 56^{\prime} 36^{\prime \prime}$ \\
Longitude E & $86^{\circ} 48^{\prime} 40^{\prime}$, & $86^{\circ} 47^{\prime} 46^{\prime}$, & $86^{\circ} 46^{\prime} 19^{\prime}$, & $86^{\circ} 46^{\prime} 26^{\prime \prime}$ \\
Max depth (m) & 8.2 & 20 & 3 & 2 \\
Lake area $\left(\mathrm{m}^{2} \times 10^{3}\right)$ & 5.7 & 41.2 & 4.2 & 6.3 \\
Catchment area $\left(\mathrm{km}^{2}\right)$ & 0.794 & 0.576 & 0.203 & 0.050 \\
pH & 7.6 & 6.4 & 7.5 & 7.4 \\
Conductivity $20^{\circ} \mathrm{C} \mu \mathrm{S} \mathrm{cm}^{-1}$ & 25 & 8 & 11 & 16 \\
\hline
\end{tabular}

Of the 90 lakes identified in the region, 65 (with LCN between 1 and 72) are in the first sub-basin, while lakes LCN74-77, belong to the second basin; and 7 lakes (LCN57-61, 64 and 65) are considered as lying outside the watershed (Tartari et al. 1998). D himalaya lakes belong to the first sub-basin, while the other daphniid species, $D$ longispina, can be found in both basins. Overall, the atmospheric deposition chemistry of the area is characterized by an extremely low overall solute content $\left(<40 \mu \mathrm{eql}^{-1}\right)$, around a third of which consists of $\mathrm{Na}^{+}$ and $\mathrm{Cl}^{-}$of marine origin, and a total inorganic nitrogen concentration of $5 \mu \mathrm{eql}^{-1}$. The ionic content of the water in these lakes is derived primarily from weathering of the rocks in the watershed. The four D. himalaya lakes are among those having no extensive stretches of glacier in their watershed, and glacial silt was not detected when sampled. Interestingly, the concentration of nitrate and total nitrogen were not different from those of main ions, indicating the different origin of nitrogen, which comes mainly from atmospheric deposition in the case of nitrogen and ammonium, compared to ions derived from weathering. However, due to the low conductivity of our lakes of interest, it would appear that the main source of water comes in the form of precipitation (Kang et al. 2002; Reynolds 1998). Thus we hypothesize that precipitation and subsequent ground water inflow (conductivity 8-10 meql ${ }^{-1}$, Reynolds 1998) and not weathering, are the main sources of ions for $D$. himalaya lakes, helping to explain the species need for an osmoregulatory system.

Although the development of the nuchal organ during embryogenesis has not been explicitly described, a recent detailed description of embryogenesis of two Daphnia species (D. hyalina and D. galeata), reports the presence of the nuchal organ (Kotov \& Boikova 2001). In their figures the nuchal organ is indicated as the dorsal organ only in the last embryo stage. However, it is possible to observe from their SEM images that the nuchal organ is well defined at the II embryo stage in $D$. galeata ( $\sim 25$ hours) and is still present in 1 hour old neonates (approximately 53 hours of embryonic development). The location of the nuchal organ is that typical of a Daphnia, i.e. opposite to the third antennae muscle, a position suggested as a diagnostic trait for the distinction between Ctenodaphnia and Daphnia by Schwartz
\& Hebert (1984), although, as later suggested by Benzie (2005) the deviation of a Ctenodaphnia species from this pattern $(D$. lumholtzi) may be indicative of the fact that this organ simply marks the joint between cephalic and dorsal shields on the dorsal margin. As the two daphnids investigated by Kotov \& Boikova (2001) do not belong to the Ctenodaphnia but yet retain the location of the nuchal organ as seen in our species, we agree with Benzie's conclusions. Benzie also suggests, in agreement with Manca et al. (1999), that the nuchal organ is present until after the first moult, even if it becomes inactive a few hours after hatching as previously reported (Peters \& de Bernardi 1987).

The cuticle covering the nuchal organ is considered permeable to ions, explaining the visible difference in carapace morphology (Halcrow 1982). It is interesting to note that the nuchal organ appears to recede into the carapace as the organism grows in its first neonate stage, making it difficult to detect its presence without the use of a SEM (Fig. 3). Thus, because of the short duration of this stage at room temperature (Halcrow 1982) it is possible that the nuchal organ recedes so quickly as to not be visible at all using conventional light microscopy, and therefore could be present in more Daphnia species than previously suspected. Also, the low temperature conditions of the alpine lakes where D. himalaya are found account for the long duration of this stage, making it possible for multiple $1^{\text {st }}$ stage neonates to coexist and leave behind an increasing number of head shields in the sediment at one time. Further research needs to be done on the presence of a nuchal organ in other species, especially those found in cold climates, and also to investigate its presence through the developmental stages as it relates to changes in conductivity.

The collection efforts of EV-K ${ }^{2}$-CNR Project are the first to deduce the presence of the nuchal organ from sediment remains and to show the presence of the nuchal organ in Daphnia from field samples taken in extreme freshwater environments. All other Daphnia research on the nuchal organ has relied on laboratory cultures. As temperature plays a key role in the time between stages, the lower temperatures of alpine lakes (between 5.6 and $7.1^{\circ} \mathrm{C}$, depth differences) are ideal for extending the duration between stages. This makes it possible to collect 
many Daphnia still in an early stage of development, as clutches may overlap, thus allowing for the detection of the nuchal organ in collected samples. It is invaluable for taxonomic and biogeographic studies for sampling efforts to try and reach as many varied locations as possible, as the findings and research endeavors that have resulted from the EV-K ${ }^{2}$-CNR Project collection efforts demonstrates. It is also important to study these regions as valuable information regarding the fauna of these remote lakes can be lost rapidly: for instance, sediment samples have shown that $D$. himalaya has recently disappeared from lakes in the region, probably as a consequence of changes related to global pressures (Manca \& Comoli 2004; Manca et al. 1999). Due to their interesting morphological and physiological properties further work needs to be done to try to understand and conserve these treasures of biological diversity.

\section{ACKNOWLEDGEMENTS}

This study was carried out within the framework of the Ev-K${ }^{2}-\mathrm{CNR}$ "Scientific and Technological Research in Himalaya and Karakorum" Project with support from the Ev-K ${ }^{2}$-CNR Committee and in collaboration with the Nepal Academy of Science and Technology (NAST) as foreseen by the Memorandum of Understanding between the Government of the Kingdom of Nepal and the Government of the Republic of Italy. The research conducted was also made possible thanks to contributions from the Italian National Research Council and the Italian Ministry of Foreign Affairs. We also thank Pier Davide Pozzo, CNR-ISMAC, Institute for Macromolecular Studies, Department of Biella, Italy for his kind assistance and use of his SEM facility.

\section{REFERENCES}

Aladin, N.V. 1991. Salinity Tolerance and Morphology of the Osmoregulation Organs in Cladocera with Special Reference to Cladocera from the Aral Sea. Hydrobiologia, 225: 291-299.

Benzie, J.A.H. 2005. The genus Daphnia (including Daphniopsis) (Anomopoda: Daphnidae). Guides to the identification of the microinvertebrates of the continental waters of the world. Dumont, H.J.F. (Ed.). Backhuys Publishers, Leiden, 2005: 376 pp.

Edmondson, W.T. 1955. The seasonal life history of Daphnia in an Artic Lake. Ecology, 36: 439-455.

Fryer, G. 1987. Morphology and the Classification of the SoCalled Cladocera. Hydrobiologia, 145: 19-28.

Günzl, H. 1978. Der Ankerapparat von Sida crystallina (Crustacea, Cladocera). I Bau und Funktion. Zoomorphology, 90: 197-204.

Günzl, H. 1980. Der Ankerapparat von Sida crystallina (Crustacea, Cladocera). II Feinbau und neubildung. Zoomorphology, 95: 149-157.

Halcrow, K. 1982. Some Ultrastructural Features of the Nuchal Organ of Daphnia magna Straus (Crustacea, Branchiopoda). Can. J. Zool., 60(6): 1257-1264.

Halcrow, K. 1985. A Note on the Significance of the Neck Organ of Leptodora kindtii (Focke) (Crustacea, Cladocera). Can. J. Zool., 63(3): 738-740.
Hedin, S. 1907. Scientific results of a journey in Central Asia 1899 to1902 Central and West Tibet. Vol. 3. Stockholm.

Kang, S., P. Mayewsky, D. Qin, Y. Hou, D. Zhang, J. Ren \& K. Kruetz. 2002. Glaciochemical records from a Mt. Everest ice core: relationship to atmospheric circulation over Asia. Atmos. Environ., 36(21): 3351-3361.

Kotov, A. \& O.S. Boikova. 2001. Study of the late embryogenesis of Daphnia (Anomopoda, 'Cladocera', Branchiopoda) and a comparison of development in Anomopoda and Ctenopoda. Hydrobiologia, 442(1-3): 127-143.

Manca, M., D. Ruggiu, P. Panzani, A. Asioli, G. Mura \& A. Nocentini. 1998. Report of a collection of aquatic organisms from high mountain lakes in the Khumbu valley (Nepalese Himalayas). Mem.Ist. Ital. Idrobiol., 57: 77-98.

Manca, M., P. Comoli \& F. Margaritora. 1999. An unusual type of Daphnia head shields from plankton and sediments of Himalayan lakes. J. Limnol., 58(1): 29-32.

Manca, M. \& P. Comoli. 2004. Reconstructing long-term changes in Daphnia's body size from subfossil remains in sediments of a small lake in the Himalayas. $J$. Paleolimnol., 32(1): 95-107.

Manca, M., P. Martin, D.C. Peñalva-Arana \& J.A.H. Benzie. 2006. Re-description of Daphnia (Ctenodaphnia) from lakes in the Khumbu Region, Nepalese Himalayas, with the erection of a new species, Daphnia himalaya, and a note on an intersex individual. J. Limnol., 65(2): 132-140.

Meurice, J.C. \& G. Goffinet. 1983. Ultrastructural Evidence of the Ion-Transporting Role of the Adult and Larval Neck Organ of the Marine Gymnomeran Cladocera (Crustacea, Branchiopoda). Cell and Tissue Research, 234(2): 351-363.

Meyer-Rocow, V.B. 1979. The attachment mechanism of the waterflea Simocephalus. Microscopy, 33: 551-553.

Monoyer, P. \& J. Bussers. 1978. Etude morphologique de l'organe nucal, de l'organe frontal, de appendices et du tegument de trois especes des Cladoceres (Podon leuckarti, G. E. Sars, 1861; Podon intermedius, Lilljeborg, 1853; Evadne nordmanni, Loven, 1835) de la Mer du Nord. Comptes Rendus de l'Academie des Sciences Serie D, 287: 321-323.

Olesen, J. 1996. External morphology and phylogenetic significance of the dorsal/neck organ in the Conchostraca and the head pores of the cladoceran family Chydoridae (Crustacea, Branchiopoda). Hydrobiologia, 330: 213-226.

Peters, R.H. \& R. de Bernardi, editors. 1987. Daphnia. Mem. Ist. Ital. Idrobiol., 45: $502 \mathrm{pp}$.

Peters, R.H. 1987. Metabolism in Daphnia. Mem. Ist. Ital. Idrobiol., 45: 193-243.

Reynolds, J. 1998. High-altitude glacial lake hazard assessment and mitigation: a Himalayan perspective. In: J. Maund \& M. Eddleston (Eds), Geohazards in engineering geology. London: Engineering Geology Special Publications: 25-34.

Schwartz, S.S. \& P.D.N. Hebert. 1984. Subgeneric distinction in the genus Daphnia: a new diagnostic trait. Trans. Am. Microsc. Soc., 103(4): 341-346.

Scourfield, D.J. 1943. The post-embryonal development of Daphnia magna. J. Queckett Microsc. Club Sec., 4(1): 276283.

Tartari, G.A., G. Tartari. \& R. Mosello. 1998. Water Chemistry of high altitude lakes in the Khumbu and Imja Kola Valleys (Nepalese Himalayas). Mem. Ist. Ital. Idrobiol., 57: 51-76.

Wagler, E. 1936. Die Sistematik und geographische verbreitung des genus Daphnia mit besonderer Berucksichtigung der sudafrikanischen arten. Arch. Hydrobiol., 10: 505-556.

Received: October 2007

Accepted: November 2007 